\title{
Total Ozone Content Trend during the Last Decade over Western Indian Tropical Station i.e. Udaipur
}

\author{
Abhishek Saxena, Brij Mohan Vyas \\ Department of Physics, M. L. Sukhadia University, Udaipur, India \\ Email: saxenaabhishek85@gmail.com,bmvyas@yahoo.com
}

Received 25 January 2016; accepted 11 June 2016; published 14 June 2016

Copyright (C) 2016 by authors and Scientific Research Publishing Inc.

This work is licensed under the Creative Commons Attribution International License (CC BY). http://creativecommons.org/licenses/by/4.0/

(c) (i) Open Access

\section{Abstract}

This study focuses on multi-year change in Total Ozone Content (TOC) values measured simultaneously by ground based instrument, i.e., MICROTOPS-II sun photometer and space based TOMS satellite experiment during the last decade, i.e., the period from 2002 to 2009 in the outskirts of the semi-arid and semi-urban tropical region of Udaipur $\left(24.6^{\circ} \mathrm{N}, 74^{\circ} \mathrm{E} ; 580 \mathrm{~m}\right.$ asl), India. The negative declining trend in TOC value has been detected about 2 DU/decade by using Linear Regression Analysis (LRA) of the monthly averaged TOC levels. The LRA presents the best statistically significant percentage level (p) of greater than $99 \%$. From the comparison of present result with the observations reported over mid, high and polar latitude sites, long-term TOC variability from tropical site is found to be the lowest, followed by their intermediate range from 10 to $30 \mathrm{DU} /$ decade over mid latitude sites and the highest range from 30 to $50 \mathrm{DU} /$ decade over high to polar latitude. In order to establish the possible linking of reduction in TOC level per decade with other stratospheric dynamic parameters and atmospheric UV aerosols parameter, inter-annual change in average monthly TOC level has shown a strong correlation coefficient $(r)$ of the order of $0.73(p>$ 99.9990) with the stratospheric temperature, followed by its observed lower $r$ value of $0.25(p=$ 99\%) for stratospheric zonal wind and then a significant correlation $(r=0.17 ; p=95 \%)$ for AI 300 $\mathrm{nm}$ (Aerosols Index $300 \mathrm{~nm}$ ) parameter. The variation of monthly mean meridional wind component does not illustrate a statistically significant correlation $(r=0.13 ; p<80 \%)$ with their respective multi-year change in mean monthly TOC values. The consequence of such reduction of TOC per decade may be identified as the result of expected enhancement in incident ground UV-radiation level. At the same time, the harmful influence of increasing the UV level seems to be counteracted and reduced with the evidence of observed higher level of $A I$ at $300 \mathrm{~nm}$ as high as 3 in the summer months over selected tropical environmental site.

\section{Keywords}

Total Ozone Content, AI 300 nm, Stratospheric Parameters, Tropical Latitude 


\section{Introduction}

Atmospheric ozone is one of the leading minor Earth chemical constituents as well as positive Earth's atmospheric radiative forcing active species [1] [2]. It absorbs completely solar ultraviolet (UV-A) radiation below $280 \mathrm{~nm}$ and partially attenuates UV-B (Ultra-Violet-Biological Radiation) solar radiation between $290-320 \mathrm{~nm}$ along with absorbing the on-going reflected terrestrial Infrared (IR) radiation, i.e., perturbs the radiative energy balance of the upper troposphere and lower stratosphere [3]. Therefore, the stratospheric ozone generated through photochemical processes provides a protective layer shielding to the Earth environment against the attenuation of harmful solar UV-B radiation in stratospheric height from 15 to $40 \mathrm{Km}$ and saves the public health as well as an eco-vegetations of the surrounding region around observing location. It, further, influences the atmospheric stability of thermal structure, i.e., cooling and warming effect in accordance with depletion and enhancement of TOC [4]-[7]. At the same time, ozone available over the Earth's surface to $10 \mathrm{Km}$ (Troposphere) is produced mainly by anthropogenic activities and exhibits harmful effect on natural vegetation, air quality, human health, Earth's atmospheric climate change, etc., even their availability of small concentration in parts per billion levels [1]. As a result, atmospheric ozone, available at various altitudes from Earth's surface to troposphere and stratosphere, behaves as the dual nature like as either a bad or a good ozone, respectively [7]-[9].

Since stratospheric ozone concentrations share about more than $90 \%$ of the Total Ozone Content (TOC) amount in the Earth's atmosphere, and it shields from dangerous solar incident UV radiation to our human being life on the Earth system. It has furthermore implication to global environmental and Earth climate issue, i.e., radiative forcing of climate [3] [9]. In addition to this, recent studies have also given the evidence about the consequences of the reduction of TOC in term of enhancement of ground level solar UV radiation intensities. Their findings highlighted that about 1\% decrease TOC in DU (Dobson Unit, a unit of TOC) could cause about $2 \%$ increment in the UV-B radiation [10]-[15].

With views of the above importance of perturbation on ground level reaching to the net solar UV radiation irradiation intensity and their serious impact on the human health and environmental change assessment, stratospheric ozone or TOC investigations have been the cynosure for atmospheric scientists and common person's life. Thus, numerous kinds of atmospheric ozone studies were conducted in past decades to elucidate the TOC variability over the distinct geographical and environmental locations along with in special time scales ranging from solar cycle (11 years) to planetary wave scale (few days) etc. [16]-[24]. Since after motivation from the greatest scientific discovery of the present century, i.e., the "Ozone Hole" over Antarctica by Farman [10], the assessment of year to year change in TOC over various parts of the world has been further motivated. Therefore, now it becomes a frontier research topic, which is seriously concerned with global environmental warming issue [17] [18] [21] [25]-[30]. In the past one decade, several investigations over various parts of the world as well as also over Indian sites, based on both ground and satellites based TOC measurements, have been reported with emphasis on investigating the long term change in TOC over tropical sites. Their investigations bring out an overall declining trend of the TOC with various variability levels as high as 30 DU/decade to a minimum level of 2 DU/ decade over northern high, mid and low latitude stations [16] [17] [21] [31]-[36].

In extended to such studies in more details, large numbers of researchers have proposed hypothesis and possible causes of negative trend of the TOC on the basis of several new pathways contributing to atmospheric ozone depletion phenomena time to time. They have made an attempt to establish the inter link between long-term change in TOC with atmospheric dynamics and chemistry coupled processes parameters like emission of Ozone Depleted Substance (ODS) as chemical catalyst Chlorofluorocarbons (CFCs), etc., stratospheric temperature, stratospheric cooling, El-Nino phenomena, planetary wave activity, tropopause height, cosmic ray, thunderstorm activities [19] [28] [37]-[43].

In this context, over Indian site, the first ever observation about the reducing trend of TOC per decade was reported by Chakrabarty [5]. Subsequently, long-term trend analysis of TOC was also discussed by Indian researchers [5] [6] [21] [23] [36]. Such findings have been creating a lot of attention and interest to motivate to carry out further more in depth investigation of long-term changes in TOC along with special highlighting on their identifications of their possible causes. Most of such past studies over Indian region have been focused on the negative trend of TOC per decade with varying amount depending upon the locations. Their results have given the indication about the greater rate of annual TOC declining of 9 DU/decade over the Northern Indian zone, when compared to the central Indian region, where the annual declining trend is found of the 3 - 5 DU/ decade. However, the statistically insignificant long-term TOC declining trend less than 1 DU/decade is ob- 
served over the southern Indian region.

It is more worthwhile to be noticed at this stage that, in the special reference to the tropical climate region, where nearly $40 \%$ of global atmospheric ozone is generated through the photochemical reactions due to the accessibility of a large plenty of incident solar radiation over the edges of this specific tropical region. But, it is transported towards higher latitudes by atmospheric transport dynamic mechanisms (e.g. Brewer-Dobson circulation). Thus, an excessive amount of ozone accumulates at higher latitudes relative to the lower latitudes, where it is created [28].

Above and beyond this, net TOC over tropical latitudes is affected not only by the absorption of UV-B radiation, but all together it is also affected by clouds, aerosols, large-scale atmospheric transportation or stratospheric dynamics phenomena (i.e., Brewer-Dobson circulation) as well as reactions to long-lived chemicals in the atmosphere acting as catalysts, such as chlorine, bromine, hydrogen, and nitrogen (chlorofluorocarbons), especially at low temperatures [2] [14] [44].

Realizing the above facts kept in mind, there are either very few or rare investigations on its identification of its possible causes of the declining TOC trend over Indian tropical zone, except by Vyas and Saraswat [23]. Thus, in order to capture the most possible causes of the ozone depletion level and their consequences on feasible enhancing of ground level reaching the dangerous solar UV-A and UV-B radiation band for human health, controlling the role of affecting the thermal structure of atmosphere etc., an attempt has been made in this paper to quantify the trend analysis of TOC variability on basis of averaged multiyear monthly TOC values over tropical station like Udaipur $\left(24.6^{\circ} \mathrm{N}, 74^{\circ} \mathrm{E}\right.$; $580 \mathrm{~m}$ asl) along with to ascertain their inter-correlation between the declining trend of TOC with other new most relevant atmospheric parameters like Aerosols Index at $300 \mathrm{~nm}$ (AI $300 \mathrm{~nm})$, stratospheric air temperature $\left(\mathrm{AT}, \mathrm{T}^{\circ} \mathrm{C}\right)$ at $30 \mathrm{mb}$, zonal wind velocity $(\mathrm{V}, \mathrm{m} / \mathrm{s})$ and meridional wind velocity component $(\mathrm{U}, \mathrm{m} / \mathrm{s})$. As such these atmospheric dynamics and $\mathrm{UV}$ absorption aerosol index parameters are especially considered in the course of the work in views of that tropical ozone concentration is predominantly governed through several mechanisms, i.e., photochemical, chemical and atmospheric dynamic transport processes or incident ground UV radiation level, aerosols, cloud and meteorological parameters, etc. [11] [23] [24].

\section{Data Analysis}

The basis of the present study is comprised of daily value data set of TOC and AI300 nm collected by Total Ozone Mapping Spectrometer (TOMS) and Ozone Monitoring Instrument (OMI) on-board flown on the Earth Probe (NASA) during the period 2002 to December 2003 and the Dutch-Finnish Aura satellite during 2004 to 2009. These day to day values of TOC and AI300 nm data over Udaipur site are accessed from their websites at http://toms.gsfc.nasa.gov and http://aura.gsfc.nasa.gov. Several other concerned atmospheric parameters at stratospheric height for each monthly value have been downloaded for the similar geographical coordinate systems from NOAA website i.e., http://www.ready.noaa.gov. From the available such daily values of the TOC of the complete study period, the monthly mean values are calculated for their respective months of the years. The variations in monthly mean values of TOC have been plotted with function of months depicted for the entire study period. In order to quantify the trend analysis of change in TOC and to identify their possible causes, variations of monthly mean values of other atmospheric parameters like AI300 nm, U, V wind components and AT at $30 \mathrm{mb}$ over the same study period along with their corresponding monthly TOC variations are illustrated in the same figures to correlate the declining trend of the TOC with selected parameters. Furthermore, for statistical analysis of inter-annual yearly change in the TOC, the linearly fitted line has been also plotted on the basis of its statistical linear regression analysis. The statistically linearly regression fit line is illustrated along with their observed trend in the respective figures (Figure 1(a), Figure 1(b)). The slope, correlation coefficient (in term of $\mathrm{r}$ ) values and number of data points $(\mathrm{N})$ are depicted in each respective figure, which gives the inference about multi-year TOC variable and its statistical significance relevance level, respectively (Figure 1(a), Figure 1(b)) represent the monthly change in TOC derived from TOMS and as well as from the measurement of TOC values obtained from MICROTOPS-II Sun Photometer Ozonometer (M/s Solar Light Co. USA, Model-541) at Udaipur for selecting study years from 2002-2009. Likewise, the monthly multi-year variations in TOC measured from TOMS along with retrieved stratospheric parameters, i.e., U, V, AT at $30 \mathrm{mb}$ and AI $300 \mathrm{~nm}$ have been also displayed in Figures 2(a)-(d). 


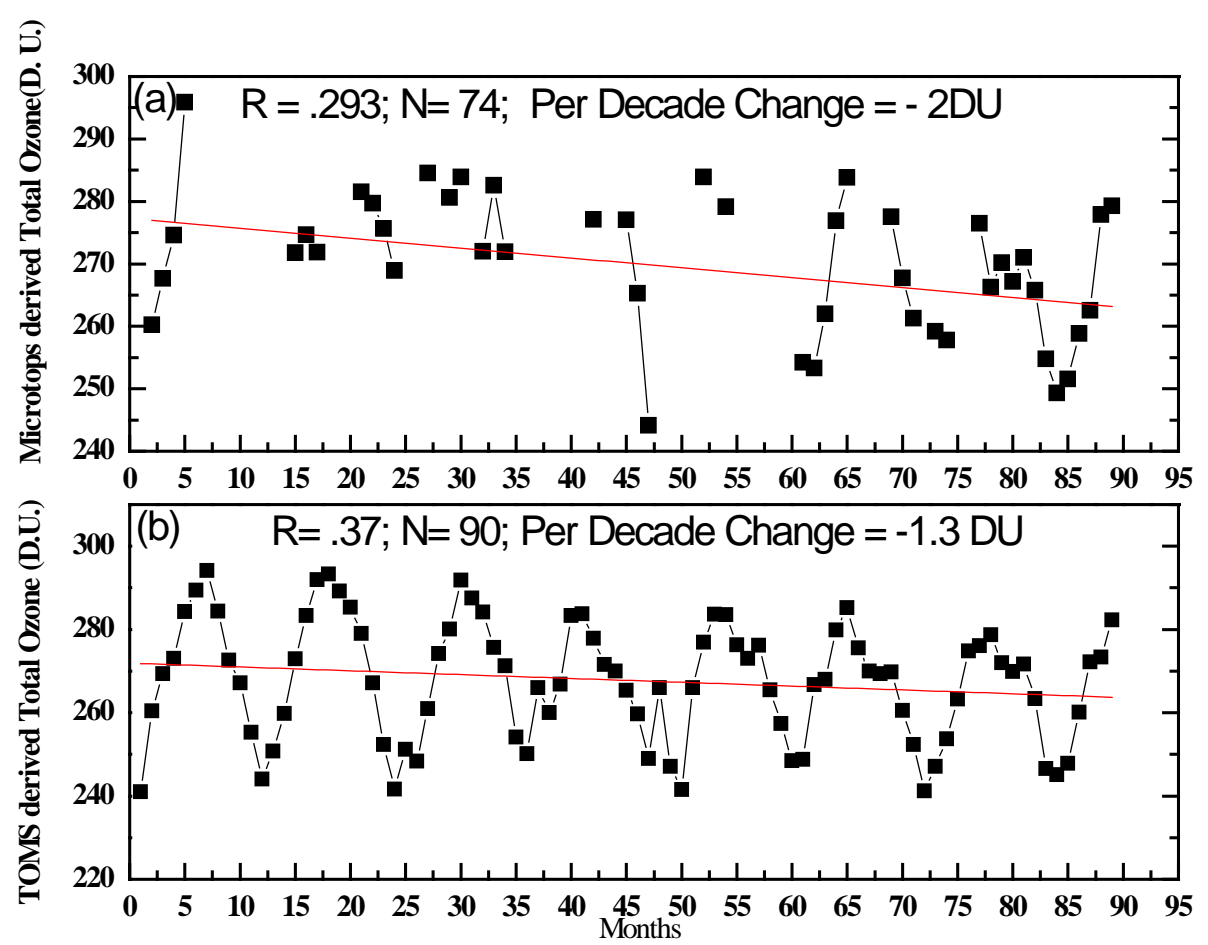

Figure 1. (a) (b) Monthly averaged variation of micro tops II derived total ozone content \& TOMS derived during year from 2002 to 2009 over Udaipur.

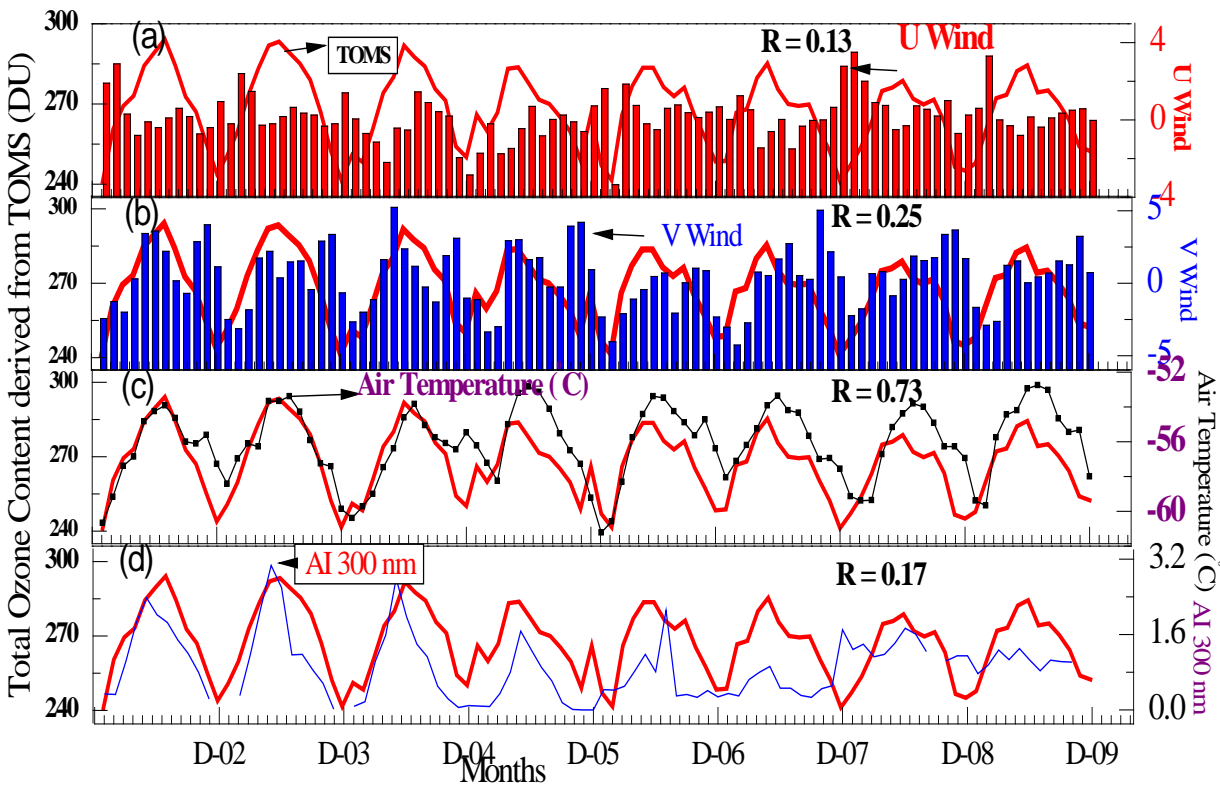

Figure 2. (a)-(d) Comparative average monthly behavior of Total Ozone Content (TOC) derived from TOMS along with merdional wind velocity (U-wind(m/sec)), (V-wind(m/sec)), Air Temperature at $30 \mathrm{mb} \&$ AI $300 \mathrm{~nm}$ during period from Jan., 2002 to Dec.,2009 over Udaipur.

\section{Results}

Figure 1(a) and Figure 1(b) represent year to year variations in averaged monthly TOC values measured from MICROTOPS-II and the satellite observations during the selected study period. It is observed from the figures that monthly TOC value is found to be highest in all the June months of each year. However, such highest 
monthly TOC observed from MICROTOPS-II is showing a good systematic decreasing trend from 297 to 283 DU or 14 DU during 2002-2009. Likewise, from satellite observations, the corresponding highest monthly average TOC magnitudes are also seen in June months, which vary from 294 to 283 DU for the same observation period. Moreover, the lowest monthly TOC levels always appearing in December months, which are in a lesser range from 240 to 245 and 245 to 259 DU derived from satellite technique and MICROOPS-II, respectively. Thus, there is a distinct declining change in the highest TOC level of 14 to 11 DU in nine years, but, in case of the lowest TOC monthly levels alter from 5 to 14 DU in nine year period. From the linear regression analysis and its related estimated parameters such as slope and correlation coefficient value, it is observed as a quite statistically relevant fact that the best statistically significant declining trend in the TOC of about 2 DU/decade is estimated from Ground Based measurements i.e., MICROTOPS-II Sun photometer with it a strong significance level 99\% ( $\mathrm{p}<0.01$ ). However, measurements of TOC from the satellite based technique, a similar appreciable variation of negative decadal change in TOC value of $1.3 \mathrm{DU} /$ decade is also found along with also better significance of confidence level $99.9 \%$ ( $p<0.001$ ). Thus, it is imperative to say that the average monthly variation of TOC values during the observation period from ground based as well as spaced based experiment displays the decreasing behaviour in TOC magnitude in almost of the same order of about $2 \mathrm{DU} /$ decade during the selected observation period over observing site.

The investigations of long-term change in TOC have been reported in the past many years by earlier researchers from the Arctic, high latitude stations [32] [45] as well as mid latitude sites [27] [31] [33] [46]. However, on the basis of their observations about the long-term change in TOC values over 13 Antarctic stations, Bojkov [26] has documented the maximum decadal change in TOC value from 35 to 50 DU/decade. Yet, Goodson (1960) has also demonstrated about the negative trend of TOC magnitude 50 DU/decade on the basis of average monthly TOC over the Arctic region. On the other hand, the ozone depletion trend is also described in range between 25 and 30 DU per decade over mid latitude stations [1] [6] [33]. The negative reducing changes in TOC are also documented in the inferior range from 3 to 10 DU/decade along with a variable rate of decreasing levels in TOC/decade over several Indian-subcontinent regions [16] [21] [22] [42]. Such depletion in ozone trend has been detected to be the highest magnitude varying from -7 to -15 DU/decade over Northern Indian region locations, at lower values from -2 to -5 DU/decade over the central Indian part and an insignificant trend about less than -1 DU/decade over the equatorial region or southern Indian site [21] [34]-[36]. Referring to the above results over varieties of distinct geographical locations and environmental conditions region, it is rather imperative to say from the previously reported results and present observations that rate of decreasing the decadal change in TOC level systematically reduces, as we shift from polar to low latitude region and furthermore toward equatorial latitude zone. However, in the present work, the estimated decadal declining trend of TOC value is reported to be the minimum of the order $2 \mathrm{DU}$ per decade, which is lower than observed declining the change in TOC value of the order 7 to 15 DU per decade over other northern Indian tropical stations. However, it is comparable and consistent with the value of observing central Indian sites. Hence, the about the present reported findings concerning the order of reducing the TOC magnitude about 2 DU/decade is corroborated and matched with the earlier reported results over the central part of Indian region and lower than they observed TOC declining trend over northern Indian regions.

In order to establish possible linkage of present lower declining long term TOC trends along with the similar variation of monthly mean wind components, i.e., $\mathrm{U}, \mathrm{V}$ and AT at $30 \mathrm{mb}$, AI $300 \mathrm{~nm}$, the average monthly behaviour of TOC are also illustrated by different color lines along with the average monthly variations in U, V, AT at $30 \mathrm{mb}$ and AI300 nm for the entire experimental period for similar geographical location in Figures 2(a)-(d). From the close look to Figure 2(a), it is noticed that meridional wind is mainly weak, i.e., less than \pm 4 $\mathrm{m} / \mathrm{s}$, in general the northward meridional wind coincides with the occurrence of a lower TOC value. Unlike to this, the peak TOC value may be noticed during observing southward meridional wind. Nevertheless, on the basis of statistical analysis inferences, a very poor correlation coefficient value (0.13) with insignificant statistical level is seen in the case of the correlation of the TOC with U. This month to month change in TOC magnitudes didn't show any much dependence with the U.

The year to year variation of monthly average TOC level along with their mean monthly zonal wind velocity component is depicted in Figure 2(b). The zonal wind is primarily found westward in the winter month with the concurrence of observing lower TOC values and, then it turns systematically from westward to eastward during April to November of yielding with their higher TOC level. Therefore, zonal wind shows close resemblance with the average monthly TOC parameter (Figure 2(b)). It is interesting to be noticed from the first look to plots 
that the average TOC magnitudes and zonal wind speed both change in accordance with almost in their same phase. The lowest TOC values correspond to prevailing higher westward wind component, in contrary to this, the higher TOC values are seen in June month, when the zonal wind remains mainly toward east. Hence, the monthly TOC amount increases in accordance with the decreasing of westward or increasing eastward wind speed or vice versa. On the basis of computing statistical parameters, such as $\mathrm{r}$ and $\mathrm{p}$, the good statistical correlation coefficient value of 0.25 with the percentage of significance level above $95 \%$ is noted between the their TOC and zonal wind component, which further support the confirmation the positive relation with their observed monthly TOC and the zonal wind velocity.

Figure 2(c) gives the comparative views of observed monthly average TOC values vary with their respective stratospheric atmospheric temperature (AT at $30 \mathrm{mb}$ ) for the entire selected study period. The monthly behaviour of TOC is seen to be varied exactly in similar fashion with their month to month change in the AT. The mean monthly TOC and AT values both increases in the same phase after attaining their minimum values of about $241 \mathrm{DU}$ and $-61^{\circ} \mathrm{C}$ in January. After that their values showed to begin their growing level and, attained their peak values about $297 \mathrm{DU}$ and $-53^{\circ} \mathrm{C}$ in June month. Subsequently, their levels go down onward July to attain their original values around $241 \mathrm{DU}$ and $-61^{\circ} \mathrm{C}$ in December. It is more worthwhile to be noticed at this junction that the monthly values of AT at $30 \mathrm{mb}$ are also found to be the highest in June and the lowest in December, which trend is quite comparable in nature to mean monthly behaviour of TOC. But, the reduction in the highest TOC values from 297 to 283 DU has coincided with a similar period of more enhancements in AT at 30 $\mathrm{mb}$ from $-52^{\circ} \mathrm{C}$ to $-56^{\circ} \mathrm{C}$ (Figure 2(c)). Therefore, the increase or decrease in highest TOC values fluctuates accordingly to corresponding increases or decreases in the air temperature. It gives clearest indication about the warming of the stratosphere in summer months. It may attribute to perturbation in photochemical activity of ozone destruction in atomic oxygen and molecular oxygen under the presence of incident solar UV-B radiation and ODS substances. It is, therefore, further responsible for altering the thermal structures of stratosphere. Thus, the consequence of such reduction of TOC value seems to be in two folds i.e., (1) observed in term of increase in air temperature at a stratospheric height, which is quite expected from one of the causes by more consumption of incident UV-radiation in the destruction of ozone into atomic oxygen and molecular oxygen with incident solar UV solar radiation and (2) by the presence of UV absorbing aerosol type (AI $300 \mathrm{~nm}$ value above 1.5) in the summer months [18] [43] [44]. At this juncture, it is interesting to be noted that one of strong correlation coefficient value of 0.73 along with best significance level above $99.999 \%$ is appearing between their observed monthly averaged variation of both the TOC and AT. Thus, in among of all of these chosen parameters such as $\mathrm{U}, \mathrm{V}$ and AI $300 \mathrm{~nm}$ also, the computed correlation coefficient between the TOC and the AT at $30 \mathrm{mb}$ showed their highest value along with their possessing strong statistical confidence significance level above $99.99 \%$ as compared to other remaining parameters.

The month to month change in mean TOC and AI $300 \mathrm{~nm}$ is depicted in Figure 2(d). It is observed from the figure that the monthly values also vary in similar fashion with the monthly variation of AI $300 \mathrm{~nm}$. Moreover, it can also be seen from Figure 2(d) that monthly variation of AI $300 \mathrm{~nm}$ occurs the minimum value as low as 0.2 to 0.3 in December and January or presence of lower UV absorbing aerosol type (winter months), afterward it shows the continuously increasing behaviour onward and attains its peak value as high as 1.2 to 2.6 during May and June or more occurrence of highly UV absorbing nature of aerosols. Subsequently, its value continuously decreases from summer month onward till winter months during the study period. The average monthly behaviour of AI $300 \mathrm{~nm}$ and TOC are quite analogous to each other. The occurrences of the lower value of TOC coincide with the occurrence of lower value of AI $300 \mathrm{~nm}$ or vice versa. On the basis of statistical inferences, a slightly lower correlation coefficient value of 0.17 with the computed the significance level above $95 \%$ is observed between their monthly behaviour of the TOC and AI $300 \mathrm{~nm}$

\section{Conclusions}

In this paper, the multi-year behaviour of TOC over Udaipur has been described for the period from 2002 to 2009 by using the ground based and satellite based experiment. An attempt has also been made to associate the long-term declining trend in TOC with various stratospheric dynamic and aerosol parameters like AT $30 \mathrm{mb}, \mathrm{V}$ and $\mathrm{U}$ wind component and also to AI at $300 \mathrm{~nm}$ and their interrelation with the declining trend of TOC. Based on above results with multi-year analysis of TOC and its interrelationship with stratospheric and aerosol parameters, the following main conclusions are summarised as below over the Indian tropical station. 
1) The overall declining trend in TOC value finds the order about 2 DU per decade, which is the lowest value as compared to previously reported results of high, mid and low latitude stations during past decades. On the basis of this fact, the present study suggests the consequence of declining in TOC about 2 DU/decade over tropical station may lead to perturbation in the increasing of ground level UV radiation level above $4 \%$ decade.

2) The strong negative correlation coefficient value between monthly variation of TOC and stratospheric air temperature supports the view of destruction of ozone with increase in temperature or thermal unbalance of the stratosphere. The occurrences of the lower value of TOC are also coinciding with more northward and westward wind or vice-versa. It gives further more support to the argument of TOC variability due to varying the atmospheric dynamics or transport variables over the tropical site.

3) The lower monthly TOC values are linked to the respective lower values of AI at $300 \mathrm{~nm}$ or more dominance of non-absorbing UV aerosol type. And, higher monthly TOC concentrations are associated with more presence of absorbing UV-aerosols type or higher AI $300 \mathrm{~nm}$ values. It may also be pointed out that the implication of decreasing of TOC level in summer months with corresponding increasing ground level UV-B radiation level in summer months may further coincide with the increase of availability of higher values of AI $300 \mathrm{~nm}$ or UV absorbing aerosols type.

Referring to above discussions, it may be summarised that some of the main responsible factors of declining of TOC may be linked with the coincidence of enhancement in stratospheric temperature, AI $300 \mathrm{~nm}$ and transportation of TOC due to changing in meridional and zonal wind circulation pattern during the study period along with presence of longer life ODS chemical substance as a catalyst in the stratosphere for destruction of ozone concentration.

\section{Acknowledgements}

The authors are highly indebted to UGC, New Delhi for providing full financial assistance for carrying out the present research work under the major UGC research project. The authors also feel sincerely grateful to Dr. G. Beig, IITM, Pune for their academic and constant encouragement during the course of study. The authors express their sincere thankful and highly acknowledge the used TOC, AI at $300 \mathrm{~nm}$, meteorological data downloaded through their respective websites

\section{References}

[1] Białek, M. (2006) Long-Term Changes (1980-2003) in Total Ozone Time Series over Northern Hemisphere Midlatitudes. ActaGeophysica, 54, 60-70. http://dx.doi.org/10.2478/s11600-006-0006-y

[2] Bojkov, R.D., Bishop, L. and Fioletov, V.E. (1995) Total Ozone Trends from Quality-Controlled Ground-Based Data (1964-1994). Journal of Geophysical Research: Atmospheres, 100, 25867-25876. http://dx.doi.org/10.1029/95JD02907

[3] Bojkov, R.D. (1986) The 1979-1985 Ozone Decline in the Antarctic as Reflected in Ground Based Observations. Geophysical Research Letters, 13, 1236-1239. http://dx.doi.org/10.1029/GL013i012p01236

[4] Brühl, C.H. and Crutzen, P.J. (1989) On the Disproportionate Role of Tropospheric Ozone as a Filter Against Solar UV-B Radiation. Geophysical Research Letters, 16, 703-706. http://dx.doi.org/10.1029/GL016i007p00703

[5] Chakrabarty, D.K., Peshin, S.K., Pandya, K.V. and Shah, N.C. (1998) Long-Term Trend of Ozone Column over the Indian Region. Journal of Geophysical Research: Atmospheres, 103, 19245-19251. http://dx.doi.org/10.1029/98JD00818

[6] Chandra, S., Varotsos, C. and Flynn, L.E. (1996) The Mid-Latitude Total Ozone Trends in the Northern Hemisphere. Geophysical Research Letters, 23, 555-558. http://dx.doi.org/10.1029/96GL00305

[7] Chandra, S., Ziemke, J.R., Min, W. and Read, W.G. (1998) Effects of 1997-1998 El Nino on Tropospheric Ozone and Water Vapor. Geophysical Research Letters, 25, 3867-3870. http://dx.doi.org/10.1029/98GL02695

[8] Dobson, G.M.B., Harrison, D.N. and Lawrence, J. (1927) Measurements of the Amount of Ozone in the Earth’s Atmosphere and Its Relations to Other Geophysical Conditions. Part 21. Monthly Weather Review, 55, 364. http://dx.doi.org/10.1175/1520-0493(1927)55<364d:MOTAOO>2.0.CO;2

[9] Ernest Raj, P., Sonbawne, S.M., Dani, K.K., Saha, S.K., Pandithurai, G. and Devara, P.C.S. (2009) Changes Observed in Sun Photometer Derived Total Column Ozone and Possible Implications on Surface-Reaching UV Radiation over a Tropical Indian Station. International Journal of Remote Sensing, 30, 4153-4165. http://dx.doi.org/10.1080/01431160902826584

[10] Farman, J.C., Gardiner, B.G. and Shanklin, J.D. (1985) Large Losses of Total Ozone in Antarctica Reveal Seasonal ClOx/NOx Interaction. Nature, 315, 207-210. http://dx.doi.org/10.1038/315207a0 
[11] Fusco, A.C. and Salby, M.L. (1999) Interannual Variations of Total Ozone and Their Relationship to Variations of Planetary Wave Activity. Journal of Climate, 12, 1619-1629. http://dx.doi.org/10.1175/1520-0442(1999)012<1619:IVOTOA>2.0.CO;2

[12] Ghude, S.D., Kumar, A., Jain, S.L., Arya, B.C. and Bajaj, M.M. (2005) Comparative Study of the Total Ozone Column over Maitri, Antarctica during 1997, 2002 and 2003. International Journal of Remote Sensing, 26, 3413-3421. http://dx.doi.org/10.1080/01431160500076434

[13] Ghude, S.D., Singh, S., Kulkarni, P.S., Kumar, A., Jain, S.L., Singh, R., Arya, B.C. and Shahnawaz. (2008) Observations and Model Calculations of Direct Solar UV Irradiances in the Schirmacher Region of East Antarctica. International Journal of Remote Sensing, 29, 5907-5921. http://dx.doi.org/10.1080/01431160802108505

[14] Godson, W.L. (1960) Total Ozone and the Middle Stratosphere over Arctic and Sub-Arctic Areas in Winter and spring. Quarterly Journal of the Royal Meteorological Society, 86, 301-317. http://dx.doi.org/10.1002/qj.49708636903

[15] Grant, W.B. (1988) Global Stratospheric Ozone and UVB Radiation. Science, 242, 1111. http://dx.doi.org/10.1126/science.3187538

[16] Hadjinicolaou, P., Jrrar, A., Pyle, J.A. and Bishop, L. (2002) The Dynamically Driven Long-Term Trend in Stratospheric Ozone over Northern Middle Latitudes. Quarterly Journal of the Royal Meteorological Society, 128, 1393-1412. http://dx.doi.org/10.1002/qi.200212858301

[17] Hadjinicolaou, P., Pyle, J.A., Chipperfield, M.P. and Kettleborough, J.A. (1997) Effect of Interannual Meteorological Variability on Mid-Latitude $\mathrm{O}_{3}$. Geophysical Research Letters, 24, 2993-2996. http://dx.doi.org/10.1029/97GL03055

[18] Harris, J.M., Oltmans, S.J., Tans, P.P., Evans, R.D. and Quincy, D.L. (2001) A New Method for Describing LongTerm Changes in Total Ozone. Geophysical Research Letters, 28, 4535-4538. http://dx.doi.org/10.1029/2001GL013501

[19] Harris, J.M., Oltmans, S.J., Bodeker, G.E., Stolarski, R., Evans, R.D. and Quincy, D.M. (2003) Long-Term Variations in Total Ozone Derived from Dobson and Satellite Data. Atmospheric Environment, 37, 3167-3175. http://dx.doi.org/10.1016/S1352-2310(03)00347-9

[20] Herman, J.R., Bhartia, P.K., Ziemke, J., Ahmad, Z. and Larko, D. (1996) UV-B Increases (1979-1992) from Decreases in Total Ozone. Geophysical Research Letters, 23, 2117-2120. http://dx.doi.org/10.1029/96GL01958

[21] Jain, S.L., Kulkarni, P.S., Ghude, S.D., Polade, S.D., Arya, B.C., Dubey, P.K. and Shahnawaz (2008) Trend Analysis of Total Column Ozone over New Delhi, India. MAPAN_Journal of Metrology Society of India, 23, 63-69.

[22] Varotsos, C. (2005) Airborne Measurements of Aerosol, Ozone, and Solar Ultraviolet Irradiance in the Troposphere. Journal of Geophysical Research: Atmospheres, 110, Article No. D09202. http://dx.doi.org/10.1029/2004JD005397

[23] Vyas, B.M. and Saraswat, V. (2013) Long-Term Changes in Total Ozone Column Content and Its Association with Stratospheric Temperature over Two Neighboring Tropical Asian Stations. International Journal of Remote Sensing, 34, 6496-6506. http://dx.doi.org/10.1080/01431161.2013.802827

[24] Wang, W.C., Liang, X.Z., Dudek, M.P., Pollard, D. and Thompson, S.L. (1995) Atmospheric Ozone as a Climate Gas. Atmospheric Research, 37, 247-256. http://dx.doi.org/10.1016/0169-8095(94)00080-W

[25] Varotsos, C. (2000) Atmospheric Ozone Variability: Implications for Climate Change, Human Health and Ecosystems. Springer, New York.

[26] Krizan, P., Miksovsky, J., Kozubek, M., Wang, G.C. and Bai, J.H. (2011) Long Term Variability of Total Ozone Yearly Minima and Maxima in the Latitudinal Belt from $20^{\circ} \mathrm{N}$ to $60^{\circ} \mathrm{N}$ Derived from the Merged Satellite Data in the Period 1979-2008. Advances in Space Research, 48, 2016-2022. http://dx.doi.org/10.1016/j.asr.2011.07.010

[27] Londhe, A.L., Bhosale, C.S., Kulkarni, J.R., Kumari, B.P. and Jadhav, D.B. (2003) Space-Time Variability of Ozone over the Indian Region for the Period 1981-1998. Journal of Geophysical Research: Atmospheres, 108, 8781-8786. http://dx.doi.org/10.1029/2002jd002942

[28] Mohankumar, K. (2008) Stratosphere Troposphere Interactions: An Introduction. Springer, Dordrecht, 416. http://dx.doi.org/10.1007/978-1-4020-8217-7

[29] Munro, R., Siddans, R., Reburn, W.J. and Kerridge, B.J. (1998) Direct Measurement of Tropospheric Ozone Distributions from Space. Nature, 392, 168-171. http://dx.doi.org/10.1038/32392

[30] Pandey, R. and Vyas, B.M. (2004) Study of Total Column Ozone, Precipitable Water Content and Aerosol Optical Depth at Udaipur, a Tropical Station. Current Science, 86, 305-309.

[31] Patra, P.K. and Santhanam, M.S. (2002) Comment on "Effects of Cosmic Rays on Atmospheric Chlorofluorocarbon Dissociation and Ozone Depletion”. Physical Review Letters, 89, 219803. http://dx.doi.org/10.1103/PhysRevLett.89.219803

[32] Petzoldt, K., Naujokat, B. and Neugebohren, K. (1994) Correlation between Stratospheric Temperature, Total Ozone, and Tropospheric Weather Systems. Geophysical Research Letters, 21, 1203-1206.

http://dx.doi.org/10.1029/93GL03020 
[33] Petzoldt, K. (1999) The Role of Dynamics in Total Ozone Deviations from Their Long-Term Mean over the Northern Hemisphere. Annales Geophysicae, 17, 231-241. http://dx.doi.org/10.1007/s00585-999-0231-1

[34] Ramaswamy, V., Schwarzkopf, M.D. and Randel, W.J. (1996) Fingerprint of Ozone Depletion in the Spatial and Temporal Pattern of Recent Lower-Stratospheric Cooling. Nature, 382, 616-618. http://dx.doi.org/10.1038/382616a0

[35] Saha, U., Midya, S.K. and Das, G.K. (2011) The Effect of the Variable Component of $10.7 \mathrm{~cm}$ Solar Flux on the Thunderstorm Frequency over Kolkata and Its Relation with Ozone Depletion Mechanism. Pacific Journal of Science and Technology, 12, 591-597.

[36] Sahoo, A., Sarkar, S., Singh, R.P., Kafatos, M. and Summers, M.E. (2005) Declining Trend of Total Ozone Column over the Northern Parts of India. International Journal of Remote Sensing, 26, 3433-3440. http://dx.doi.org/10.1080/01431160500076467

[37] Singh, R.P., Sarkar, S. and Singh, A. (2002) Effect of El Nino on Inter-Annual Variability of Ozone during the Period 1978-2000 over the Indian Subcontinent and China. International Journal of Remote Sensing, 23, 2449-2456. http://dx.doi.org/10.1080/01431160110075893

[38] Staehelin, J., Harris, N.R.P., Appenzeller, C. and Eberhard, J. (2001) Ozone Trends: A Review. Reviews of Geophysics, 39, 231-290. http://dx.doi.org/10.1029/1999RG000059

[39] Steinbrecht, W., Claude, H., Köhler, U. and Hoinka, K.P. (1998) Correlations between Tropopause Height and Total Ozone: Implications for Long-Term Changes. Journal of Geophysical Research: Atmospheres, 103, 19183-19192. http://dx.doi.org/10.1029/98JD01929

[40] Stolarski, R., Bojkov, R., Bishop, L., Zerefos, C., Staehelin, J. and Zawodny, J. (1992) Measured Trends in Stratospheric Ozone. Science, 256, 342-349. http://dx.doi.org/10.1126/science.256.5055.342

[41] Tandon, A. and Attri, A.K. (2011) Trends in Total Ozone Column over India: 1979-2008. Atmospheric Environment, 45, 1648-1654. http://dx.doi.org/10.1016/j.atmosenv.2011.01.008

[42] Torres, O., Bhartia, P.K., Herman, J.R., Ahmad, Z. and Gleason, J. (1998) Derivation of Aerosol Properties from Satellite Measurements of Backscattered Ultraviolet Radiation: Theoretical Basis. Journal of Geophysical Research: Atmospheres, 103, 17099-17110. http://dx.doi.org/10.1029/98JD00900

[43] Udelhofen, P.M., Gies, P., Roy, C. and Randel, W.J. (1999) Surface UV Radiation over Australia, 1979-1992: Effects of Ozone and Cloud cover Changes on Variations of UV Radiation. Journal of Geophysical Research: Atmospheres, 104, 19135-19159. http://dx.doi.org/10.1029/1999JD900306

[44] Varotsos, C. (1994) Solar Ultraviolet Radiation and Total Ozone, as Derived from Satellite and Ground-Based Instrumentation. Geophysical Research Letters, 21, 1787-1790. http://dx.doi.org/10.1029/93GL02090

[45] WMO (1999) Scientific Assessment of Ozone Depletion: 1998. Global Ozone Research and Monitoring Project-Report No. 44, World Meteorological Organization, Geneva.

[46] WMO (2003) Scientific Assessment of Ozone Depletion: 2002. Global Ozone Research and Monitoring Project—Report No. 47, World Meteorological Organization, Geneva. 